\title{
Non-normal real estate return distributions by property type in the UK
}

Article

Accepted Version

Young, M., Lee, S. and Devaney, S. (2006) Non-normal real estate return distributions by property type in the UK. Journal of Property Research, 23 (2). pp. 109-133. ISSN 1466-4453 doi: https://doi.org/10.1080/09599910600800302 Available at https://centaur.reading.ac.uk/20840/

It is advisable to refer to the publisher's version if you intend to cite from the work. See Guidance on citing.

To link to this article DOI: http://dx.doi.org/10.1080/09599910600800302

Publisher: Routledge

Publisher statement: This is an Accepted Manuscript of an article published by Taylor \& Francis in Journal of Property Research on 17/02/2007, available online: http://www.tandfonline.com/10.1080/09599910600800302

All outputs in CentAUR are protected by Intellectual Property Rights law, including copyright law. Copyright and IPR is retained by the creators or other copyright holders. Terms and conditions for use of this material are defined in the End User Agreement.

www.reading.ac.uk/centaur

\section{CentAUR}


Central Archive at the University of Reading

Reading's research outputs online 


\title{
Non-Normal Real Estate Return Distributions by Property Type in the U.K.
}

\author{
by \\ Michael S. Young \\ San Rafael, California 94903 \\ and \\ Stephen L. Lee \\ Department of Real Estate and Planning \\ University of Reading Business School \\ Whiteknights \\ Reading, RG6 6AW England \\ and \\ Steven P. Devaney \# \\ Department of Real Estate and Planning \\ University of Reading Business School \\ Whiteknights \\ Reading, RG6 6AW England \\ ${ }^{\#}$ Author for correspondence
}

This is an Accepted Manuscript of an article published by Taylor \& Francis in Journal of Property Research on 17/02/2007, available online:

http://www.tandfonline.com/10.1080/09599910600800302

The authors would like to thank Roger Brown for his helpful comments on this paper and also acknowledge the comments of the anonymous referees. The analysis was undertaken whilst one of the authors was employed at IPD, and within its confidentiality restrictions. 


\section{Non-Normal Real Estate Return Distributions by Property Type in the U.K.}

Abstract: Investment risk models with infinite variance provide a better description of distributions of individual property returns in the IPD U.K. database over the period 1981 to 2003 than normally distributed risk models. This finding mirrors results in the U.S. and Australia using identical methodology. Real estate investment risk is heteroskedastic, but the characteristic exponent of the investment risk function is constant across time - yet it may vary by property type. Asset diversification is far less effective at reducing the impact of non-systematic investment risk on real estate portfolios than in the case of assets with normally distributed investment risk. The results therefore indicate that multi-risk factor portfolio allocation models based on measures of investment codependence from finite-variance statistics are ineffective in the real estate context.

Keywords: Asset-specific risk, return distributions, non-normality, diversification 


\section{Introduction}

As institutional investors expand their options for investment opportunities to a global arena, it is helpful to have an understanding of the behavioral characteristics of assets that might be purchased individually or in portfolios. If there are characteristic performance differences among assets in different countries, these differences might lead to differences in portfolio strategies for the global investor. However, if there are similarities among investment characteristics, then investors could realize efficiencies by extending effective strategies in the home country to foreign soil.

The data and analysis of this paper extend the research presented by Young and Graff (1995). In that empirical study of disaggregated NCREIF data in the U.S., Young and Graff found that cross-sectional annual returns were not normally distributed during any year between 1978 and 1992. Additionally, the authors found that both the skewness and the magnitude of real estate risk changed over time. In a working paper, Young (2005) extended the time period to 2003 and found nearly identical results. Graff et al. (1997) examined the shape of Australian institutional real estate returns with similar results, thereby leading to the suspicion that the findings are universal. This paper carries the work one step further by applying the same methodology to U.K. data supplied by the Investment Property Databank (IPD).

All previous U.K. studies of property return distributions mentioned in the literature review below have utilized IPD data in one way or another. However, this study uses all available individual asset returns for each of the years 1981 to 2003 - amounting to 269,853 return observations in total.

With these individual institutional-grade property performance data from IPD, it is possible to test empirically the presumptions that property return distributions have finite variance and are Gaussian normal. The purpose of this study is to test whether property 
return distributions have finite variance, and to examine the implications of the test results for real estate portfolio construction and investment management.

\section{Stable Distributions}

Normal distributions are stable and are the only stable distributions with finite variance. Other examples of stable distributions are the well-known Cauchy distributions. Although most stable distributions and their probability densities cannot be described in closed mathematical form, their characteristic functions - and the logarithms of the characteristic functions - can be written in closed form. ${ }^{1}$ The $\log$ characteristic functions of stable distributions have the following form for cases where $\alpha \neq 1$ :

$$
\psi(t)=i \delta t-|x|^{\alpha}[1-i \beta \operatorname{sgn}(t) \tan (\pi \alpha / 2)]
$$

The four parameters $\alpha, \beta, \gamma$, and $\delta$ in Equation (1) completely characterize the distribution.

The characteristic exponent $\alpha$ lies in the half-open interval $(0,2]$ and measures the rate at which the tails of the density function decline to zero. The larger the value of the characteristic exponent $\alpha$, the faster the tails shrink toward zero. When $\alpha=2.0$, the distribution is normal.

While the means (first moments) of stable distributions with characteristic exponents $\alpha>1.0$ do exist, variances (second moments) do not exist-i.e., are infinite-for those distributions with Characteristic Exponents $\alpha<2.0$.

The skewness parameter $\beta$ lies in the closed interval $[-1,1]$, and is a measure of the asymmetry of the distribution. The closer the characteristic exponent $\alpha$ is to the upper limit of the permissible range - i.e., the value 2.0 - the less significance the skewness has in terms of shifting the shape of the distribution away from the corresponding symmetric

1 The normal and Cauchy distributions are the only stable distributions for which probability densities can be expressed in closed form in terms of elementary mathematical functions. 
distribution. At the limit $\alpha=2.0$, the normal distribution, the skewness parameter $\beta$ becomes irrelevant and all stable distributions are symmetric.

The scale parameter $\gamma$ lies in the open interval $(0, \infty)$, and is a measure of the spread of the distribution. If $\alpha=2.0$, the scale parameter $\gamma$ is directly proportional to the standard deviation: $\gamma=\sigma / \sqrt{ } 2$. However, the scale parameter $\gamma$ is finite for all stable distributions, despite the fact that the standard deviation is infinite for all $\alpha<2.0$. Thus, the scale parameter $\gamma$ can be regarded as a generalization of the standard deviation.

The location parameter $\delta$ may be any real number, and is a rough measure of the midpoint of the distribution. A change in $\delta$ simply shifts the graph of the distribution left or right, hence the term "location."

\section{Previous Studies}

There is a significant and growing body of literature that suggests that returns for private real estate are not normally distributed. Two approaches have been adopted in the literature: (1) time series analysis and (2) cross-sectional analysis, both of which produce similar results. We review each approach in turn.

\subsection{Time series analysis}

Myer and Webb (1994) were the first to provide evidence of non-normality in private real estate returns using data from the National Council of Real Estate Fiduciaries (NCREIF). They found evidence of non-normality in terms of both skewness and kurtosis. In similar vein, Byrne and Lee (1997) using the Jarque Bera test examined quarterly returns for sector/region disaggregations of the NCREIF index between 1983 and 1994. They found 
that, for ten of the sixteen sub-sectors, normality was rejected. Consistent with earlier findings, they found positive kurtosis and, typically, negative skewness.

In the U.K., research by Booth et al. (2002) for the Investment Property Forum tested the normality of the 37 Investment Property Databank (IPD) sectors for which monthly data existed over the period from December 1986 to December 2000, with the exception of data for shopping centres and retail warehouses, where data were from December 1994 and from December 1991 respectively. Using standard statistical tests, normality was rejected in 35 out of the 37 markets segments. The authors also examined monthly returns in the 37 sectors relative to the IPD Monthly Index, i.e., the monthly returns of each segment minus the returns of the market index. This is important for those fund managers who are active managers since the risk that they face is tracking error risk - their performance relative to the market benchmark rather than total return. In 34 out of 37 cases, the hypothesis of normality was rejected, due to 'fat tails', i.e. positive excess kurtosis. In other words, the risk of a large movement is greater than would be the case with a normal distribution.

Lee (2002) examined the distributional properties of the IPD monthly total returns data over the same period. This time, the data was divided into a number of property types and geographical regions, making a total of 31 real estate market segments. The returns of the market index (IPDMI) were represented by the value-weighted performance of all the properties within the database. He found that all market segments displayed significant positive skewness, except for offices in the City of London, which showed significantly negative skewness. In contrast, the returns of the market index were fairly symmetric. The market and all the markets segments showed significant positive excess kurtosis (i.e., greater than 3). Thus, all the time-series data were leptokurtic and so displayed greater peakedness and 'fatter tails' than would be expected if the data was normally distributed. As a consequence, all the market segments exhibited significant departures from normality at the $1 \%$ significance level, as shown by the Jarque-Bera (JB) statistic, while the returns of the market index were significant at the $10 \%$ level. 
Lizieri and Ward (2000) used the BestFit program to find the distribution that best characterized direct real estate returns in the UK. The direct real estate data comprised monthly total returns for the period from December 1986 to December 1998 as reported by IPD, with series for all property and sub-indices for specified regional and property types. They found that, irrespective of region or property type, the most appropriate distribution appeared to be the Logistic distribution, but that even this was rejected in most cases. The main reason for the inappropriate fit was the leptokurtic nature of the real estate returns.

Interestingly, de-smoothing the data to account for alleged aberrant behavior attributed to the appraisal-based nature of capital returns did not result in return distributions that were easier to model or which conformed to normality. The authors found that this resulted from the high proportion of returns that were close to zero, indicative of a thinly-traded market and slow arrival of information, resulting in static individual valuations. In other words, Lizieri and Ward (2000) found that de-smoothing monthly data does not correct for the thinness of the trading in the property market.

The same authors then examined quarterly data, arguing that, if the atypical behavior of property returns can be explained by the thinness of the market and the lack of liquidity and trading, they expected to see the distributions conform more closely to a normal distribution over longer trading intervals. The analysis of quarterly data was consistent with this conjecture. Returns were easier to model and the normal distribution was favored on a number of tests both for the aggregate index and at sub-sector level.

Brown (1991) and Brown and Matysiak (2000) investigated the return distributional properties of individual data in the UK. Brown (1991) used individual data for 135 properties, which comprised 39 offices, 46 retail and 50 industrial assets, over the period January 1979 to December 1982. On average, he found that the data were more positively skewed and leptokurtic (peaked) relative to the normal distribution, particularly in the retail sector. However, when the data were combined into portfolios, the data began to approach the normal distribution. In addition, when quarterly and half yearly data were used Brown 
(1991) found that, as the holding period gets longer, the distribution of individual returns tends towards the normal distribution, as suggested by Fama (1965a). These results were corroborated by Brown and Matysiak (2000), who examined monthly returns for two samples of 100 properties - together spanning the period December 1987 to November 1997 - and annual returns for a sample of 750 properties held over the period 1987 to 1996.

Maurer et al. (2004) compared the distributional properties of U.S., U.K., and German direct real estate returns. Using quarterly returns over the period 1987-2002 and three statistical tests (Jarque/Bera, Anderson/Darling and Shapiro/Wilks) they found that, in the case of the U.K. real estate market, normality could not be rejected as there was no significant skewness or excess kurtosis, confirming the findings of Lizieri and Ward (2000), Brown (1991) and Brown and Matysiak (2000). In contrast, both the U.S. and German real estate markets exhibited significant departures from normality, but for different reasons. In the case of the German data, normality was rejected due to significant positive skewness, while the U.S. data could not be classified as normal due to significant negative skewness and leptokurtosis (peakedness). However, once the data were de-smoothed, the results changed with normality being accepted for Germany, but rejected for the U.K. and the U.S. data. Nonetheless, when annual data were used, the assumption of normality could not be rejected for any country, either using the appraisal-based or de-smoothed data.

\subsection{Cross-sectional analysis}

Young and Graff (1995) examined the annual return distributions for U.S. institutional private real estate over the period 1980-1992. Using the NCREIF database, they decomposed individual property data (grouped by type) into two components: the mean return for a property type in any one year and a residual return for the individual property in that year. Then, using the methodology suggested by McCulloch (1986), they found that the characteristic parameter alpha for the whole sample, at 1.48 , was significantly below the 
value of 2.0 that characterizes the normal distribution, a result that held for the great majority of years and property types. The beta parameters, the measure of skewness, were typically negative for the whole sample and significantly different from zero at the $99 \%$ confidence level. Young (2005) extended the time period to 2003 and found nearly identical results.

In Australia, Graff et al. (1997) examined the distributional characteristics of annual private real estate data from the Property Council of Australia's (PCA) Performance Index, over the period 1984-1996. Using the same methodology as Young and Graff (1995), the authors found that the mean alpha parameter, at 1.59, was again significantly below the value of 2.0 characteristic of a normal distribution. However, the betas did not give any clear indication of skewness.

In summary, a number of studies have examined the distributional properties of private real estate data at the individual, sub-market, or index level in a number of countries with broadly similar results. At the individual level, the data exhibit non-normality, mainly due to excess kurtosis (peakedness) and significant skewness, although the skew can be positive or negative depending on the country or property type. Normality is also rejected for submarket indices, again for the same reasons, especially if high frequency (monthly) data are used. However, when longer holding period (quarterly and annual) data are used, normality is less likely to be rejected and, when it is rejected, this is usually due to the existence of excess kurtosis rather than skewness. This is true for the raw or appraisal-based real estate data and for de-smoothed returns. In other words, lack of normality in real estate data is mainly due to the thinness and lack of liquidity of the market which cannot be corrected by any de-smoothing process.

This work extends the cross-sectional studies of Young and Graff (1995), Graff et al. (1997) and Young (2005) by applying the same McCulloch (1986) methodology to annual individual data in the UK over the period 1981 to 2003. 


\section{Data Description}

Property performance data in the U.K. are compiled by IPD using cash flow records supplied by major institutional investors that participate in its benchmarking services, such as insurance companies, pension funds and quoted property companies. At the end of 2004, there were 10,986 properties in the U.K. annual index with an aggregate value of over $£ 120$ billion (IPD, 2005). It is estimated that this represents $45 \%$ of the total commercial property investment market in the U.K. The data source, therefore, does not cover the entire market and it may reflect the investment preferences of its constituent funds, but it is the largest source of individual property performance data in existence.

All previous U.K. studies of property return distributions mentioned in the literature review have utilized IPD data in one way or another. However, this study uses all available individual asset returns for each of the years 1981 to 2003 - amounting to 269,853 return observations in total. These are unleveraged returns on directly held real estate assets. The main exclusion from the data were returns from properties in IPD's 'Other' category, which represents minor sectors of U.K. institutional investment in this period, such as agricultural land or leisure. The 'Other' category stood at only $3 \%$ of the value of the IPD annual index at the end of 2004 (IPD, 2005). The number of observations within each year and by sector is shown in Figure 5.

Reported returns are based on income and asset value changes (i.e., capital gains) as determined by appraisal. For some properties, monthly and quarterly frequency returns were available, but this study analyzes the full dataset of monthly, quarterly, and annually valued properties by examining annual frequency returns. All of the properties in the dataset are reappraised each December, so the annual returns reflect that calendar year. Returns from properties that were traded within a year were not included as they would not reflect an entire period's performance. 
Before beginning the data analysis, each discrete annual sample return $r_{t}$ in the data set was converted to its continuously compounded equivalent $\ln \left(1+r_{t}\right)$. These returns were then examined across all properties and within the office, retail, and industrial property types.

\section{Real Estate Return Model}

A comparison of the data in the property type sub-indices reveals significant differences among the annual returns. Our real estate market model assumes that expected variations in annual property returns due to differences in property type account for all of the differences in returns on individual properties in the IPD database.

We assume that the observed annual total return on each commercial property $p$ during the calendar year $t$ is of the following form:

$$
\mathrm{R}_{\mathrm{t}}(\mathrm{p})=\mu_{\mathrm{t}}(\mathrm{h}(\mathrm{p}))+\varepsilon_{\mathrm{t}}(\mathrm{p})
$$

where $\mathrm{h}()$ is the property type (office, retail, or industrial), $\mu_{t}()$ is the expected total return during year $t$ as a function of property type, and $\varepsilon_{\mathrm{t}}(\mathrm{p})$ is a stable (possibly, infinitevariance) random variable. In addition, we assume that, for each $t \geq 1981$, the $\varepsilon_{t}()$ are independent identically distributed random variables with characteristic exponent $\alpha_{t}>1.0$ and zero mean, and that $\varepsilon_{\mathrm{t}_{1}}\left(\mathrm{p}_{\mathrm{i}}\right)$ and $\varepsilon_{\mathrm{t}_{2}}\left(\mathrm{p}_{\mathrm{j}}\right)$ are independent for all $\mathrm{t}_{1} \neq \mathrm{t}_{2}$ and all $i$ and $j .{ }^{2}$

Under these assumptions, the random variable $\varepsilon_{\mathrm{t}}(\mathrm{p})$ corresponds to the asset-specific investment risk of property $p$ during period $t$, while the systematic and market sector real estate risk is described by the function $\mu_{\mathrm{t}}(\mathrm{h}(\mathrm{)})$.

Conventional approaches toward empirical real estate research have assumed the normal probability distribution of asset-specific risk as an act of faith, and then apply 
statistical techniques to obtain descriptions of systematic and market-sector risk. By contrast, the tests of this paper examine asset-specific investment risk under the assumptions of our model, with the objectives of (1) confirming or rejecting real-world applicability of the model, and (2) obtaining additional statistical information about the likely shape of real estate investment risk. In particular, the focus of this investigation is the test of a model for the distributional form of $\varepsilon_{\mathrm{t}}(\mathrm{p})$, the asset-specific risk.

\section{Tests and Results}

Figures 1a to 4a show the distributions of continuously compounded annual total returns for the years 1981-2003: (1) in the aggregate, and (2) by each of three property types. Superimposed upon the sample histograms are normal densities with the corresponding means and standard deviations. ${ }^{3}$ In each case, the sample density function is more peaked near the mean than the corresponding normal density, has weaker shoulders and fatter tails (i.e., is leptokurtotic), and is negatively skewed. These distinctions can be seen more clearly in the graphs of the differences between each sample density and the corresponding normal density, Figures $1 \mathrm{~b}$ to $4 \mathrm{~b} .{ }^{4}$

Before fitting stable distributions to the sample data, we corrected for possible extraneous data dispersion due to changing expected return by reducing each annual return by the corresponding sample mean for that calendar year and property type (cf. Equation

2 The assumption that $\alpha_{t}>1.0$ guarantees that the mean of $\varepsilon_{t}(p)$ exists.

3 There are 50 "bins" in the histogram that span the range from minus to plus five standard deviations. Because some samples extend beyond this range, all the samples beyond plus or minus five standard deviations are included in the two extreme bins.

$4 \quad$ This leptokurtosis may be caused by general uniformity of opinion amongst valuers as to the discount rate applicable to cash flows, as well as the use of similar valuation models. This would produce a strong convergence about a single return for property types in any particular year. Departures from this central tendency would then likely be asset-specific and relate to the economic circumstances of tenancy, for example, either new leases at higher or lower than expected rates or unexpected vacancy or occupancy. 
(2)). The means are shown in Figure 5 for purposes of completeness, but will not be needed in the subsequent discussion.

McCulloch's (1986) quantile methodology was used to fit a stable distribution to each set of residuals arranged by calendar year and property type. To test whether the parameters varied during the sample period, stable parameters were estimated for sets composed of the residuals aggregated across calendar years and property types. These results are tabulated in Figure 5 and are displayed graphically together with one and two standard deviation error bands in Figures 6 to 9 for the parameters $\alpha, \beta$, and $\gamma$ ( $\delta$ is irrelevant because the location parameter is an estimator for the mean and we adjusted for the effect of varying means).

In the case of characteristic exponents $\alpha_{t}$ estimated by calendar year and property type, $100 \%$ (69 of 69) were distinct statistically from 2.0 - the characteristic exponent of the normal distribution - with 95\% confidence and 99\% (68 of 69) were distinct from 2.0 with 99\% confidence. In the case of residuals aggregated across property type (the first panel of Figure 5), all twenty-three sample characteristic exponents $\alpha_{\mathrm{t}}$ were distinct from 2.0 with $99 \%$ confidence.

In the case of the skewness parameter $\beta_{\mathrm{t}}$ for all residuals aggregated across property type, $83 \%$ (19 of 23) were statistically significant (i.e., non-zero) with $99 \%$ confidence.

Figure 6 displays the sample characteristic exponents $\alpha_{t}$ of both the aggregated and individual property type residuals. It appears that $\alpha_{t}$ could be time-invariant. However, Figure 9, which shows graphical representations of these data, suggests that $\alpha_{t}$ is likely to vary across property type. From Figure 5, for the entire 1981 to 2003 sample period, estimates of characteristic exponents together with their standard errors are $1.448 \pm 0.004$ for all three property types combined, $1.431 \pm 0.007$ for office properties, $1.471 \pm 0.006$ for retail properties, and $1.425 \pm 0.009$ for industrial properties. 
By contrast, Figure 7 shows clearly that $\beta_{t}$ is not time-invariant. Indeed, $\beta_{t}$ for all properties displayed a roughly cyclic pattern throughout the test and seem to track one another, especially the office and industrial results.

Figure 8 shows clearly that the scale parameter $\gamma$ is not time-invariant either in the aggregate or by property type. The general time-series patterns, however, are quite similar with roughly the same peaks and valleys. Since $\gamma$ is the stable infinite-variance measure of risk, this means that asset-specific risk is heteroskedastic.

The three graphs of Figure 9 show the characteristic exponent, the skewness, and the scale parameter for each property type and the aggregate over the full 1981 to 2003 time period, along with the one- and two-sigma error bands. In terms of skewness and scale parameter, all three property type results differ statistically from one another.

Because all twenty-three sample estimators for $\alpha_{t}$ are asymptotically normal, the proposition that the true values are all equal (i.e., that $\alpha_{t}$ is time-invariant) can be tested by using the fact that, when it is true,

$$
\sum \mathrm{w}_{\mathrm{i}}\left(\mathrm{x}_{\mathrm{i}}-\overline{\mathrm{x}}\right)^{2}
$$

is distributed as $\chi^{2}$ on twenty-two degrees of freedom, where each weight $\mathrm{w}_{\mathrm{i}}$ is given by the reciprocal of the asymptotic variance of $x_{i}$, and $\bar{x}$ is the weighted average of $x_{i}$ (weighted by the $\mathrm{w}_{\mathrm{i}}$ ).

The last column of Figure 10 shows the year-by-year $\chi^{2}$ components for the sample characteristic exponents with the total for the twenty-three-year period at the bottom of the column. The total is 521.99 , which is substantially larger than the 0.05 significance level of 33.92 for twenty-two degrees of freedom. Although there are some exceptionally high $\chi^{2}$ results in the year-by-year components, only a couple of these years are notable in terms of market events or circumstances, those being the strong up market of 1988 and the down 
market of 1990 respectively. In these years, valuers may have had difficulty with exceptional uncertainty, creating these nominal outliers.

The $\chi^{2}$ test can also be used to test whether, for each year during the sample period, the individual property type $\alpha$ estimates are consistent with the hypothesis that the true values of $\alpha$ for the various property types are identical. More precisely, for each year in the sample period, let $\mathrm{P}_{\mathrm{t}}$ be the hypothesis that the true values of $\alpha$ for the three property types in year $t$ are identical (note that this does not assume that the true value for $\alpha$ is time-invariant). By computing the weighted average of sample property type $\alpha$ 's for each year, the analog of the $\chi^{2}$ test described above can be applied to test hypothesis $\mathrm{P}_{\mathrm{t}}$. This time the critical $\chi^{2}$ value is 7.81 , i.e., the 0.05 significance level of the $\chi^{2}$ function for two degrees of freedom.

The resulting twenty-three $\chi^{2}$ values are shown in the next-to-last column of Figure 10 (the corresponding $\chi^{2}$ for the data aggregated across the sample period is shown at the bottom of the column). In only $48 \%$ of the cases (11 of 23 ), the observed sample value is below the 0.05 significance level.

The analogous $\chi^{2}$ test for $\beta_{\mathrm{t}}$ can be used to test the proposition that $\beta_{\mathrm{t}}$ was timeinvariant during the test period. The last column of Figure 11 shows the year-by-year $\chi^{2}$ components of the skewness parameter, with the total for the twenty-three-year period at the bottom of the column. The total is 2058.97 , which is enormously larger than the 0.05 significance level of 33.92 for twenty-two degrees of freedom. Thus, there is no reasonable possibility that $\beta_{\mathrm{t}}$ was time-invariant during the sample period. Likewise, the individual property type $\beta$ estimates for each year of the sample period show little similarity. In only $39 \%$ of the cases ( 9 of 23 ), the observed sample value is below the 0.05 significance level.

The above analysis implies that (1) real estate investment risk during the sample period was heteroskedastic; (2) during virtually all sample sub-periods and across property type, stable infinite-variance skewed asset-specific risk functions with a characteristic exponent $\alpha$ 
of approximately 1.448 modeled the observed distributions of return residuals better than normally distributed risk candidates; and (3) property type differences in the characteristic exponent across property types are likely; certainly retail properties showed notable differences from office and industrial over the full 1981 to 2003 sample period.

\section{Implications for Portfolio Management}

In the era of Modern Portfolio Theory, the central task of portfolio management is considered to be the optimization of the portfolio return/risk trade-off, subject to investment policy constraints on construction of portfolios. This involves asset selection and allocation to achieve two independent objectives: (1) minimization of the combined effect of assetspecific risk, and (2) optimization of the trade-off between portfolio return and systematic/sector risk.

The approach to this problem most often taken in portfolio research is: (a) specify the largest tolerable combined asset-specific risk, most commonly defined by the variance; (b) calculate the minimum number of assets necessary to ensure that the combined effect of asset-specific risk is below the critical threshold; and (c) solve the trade-off problem under the additional constraint that investment funds be diversified among at least the number of assets determined in (b) for each permissible sector.

To see what is involved in satisfying the additional constraint imposed by (b) above, it is helpful to make the following simplifying assumptions: all asset-specific risk functions are stable with the same characteristic exponent $\alpha$ and have the same skewness parameter $\beta$, all individual assets have the same level of asset-specific risk (proxied by the scale parameter $\gamma$ of the distribution for the common asset-specific risk function), and the same percentage of the total portfolio value is invested in each component asset in the optimal portfolio. Then, letting $p$ represent the portfolio, $f$ the common asset-specific risk function, 
and using the relation between scale parameters of sums of stable random variables described in Equation (2): ${ }^{5}$

$$
\begin{aligned}
\gamma_{p}^{\alpha} & =\gamma_{(1 / n) f_{1}}^{\alpha}+\ldots+\gamma_{(1 / n) f_{n}}^{\alpha} \\
& =n \gamma_{(1 / n) f}^{\alpha}=n(1 / n) \gamma_{f}^{\alpha} \\
& =n(1 / n)^{\alpha} \gamma_{f}^{\alpha}=n^{(1-\alpha)} \gamma_{f}^{\alpha}
\end{aligned}
$$

This implies that:

$$
\gamma_{p}=n^{(1 / \alpha)-1} \gamma_{f}
$$

Figure 12 shows the impact of varying $\alpha$ upon reduction in asset-specific risk for various numbers of properties in a portfolio. For any given $\alpha>1.0$, the reduction in assetspecific risk increases with increasing $n$. As $\alpha$ diminishes to 1.0 from its upper limit of 2.0, the reduction in asset-specific risk likewise diminishes for any given $n>1$.

The sample value $\alpha=1.448$ from the preceding section implies the following practical estimate for the effect of portfolio diversification on asset-specific risk reduction:

$$
c_{p} \approx n^{-0.309} c_{f}
$$

A typical closed-end real estate fund or client separate account has 10 to 20 properties, and large open-end real estate funds might have about 100 properties. Under the above assumptions, the magnitude of combined asset-specific risk for such a closed-end fund or client separate account is between $40 \%$ and $49 \%$ of the magnitude of asset-specific risk for a single property portfolio. However, if the asset-specific risk were normally distributed, the combined asset-specific risk would be between $22 \%$ and $32 \%$ of the magnitude of assetspecific risk for a single property portfolio. Thus, portfolio-level risk-reduction is considerably less than has been presumed under assumptions of normal return distributions.

$5 \quad$ Cf. Fama and Miller (1972, 268-270) and Fama (1965b). 
Similarly, the magnitude of combined asset-specific risk for open-end fund of 100 properties is $24 \%$ of the magnitude of asset-specific risk for a single property portfolio. However, if the asset-specific risk were normally distributed, the combined asset-specific risk would be just $10 \%$ of the magnitude of asset-specific risk for a single property portfolio.

Alternatively, if the question of risk reduction is rephrased to ask the number of assets $\mathrm{n}_{\mathrm{k}}$ needed in a portfolio to achieve a reduction of asset-specific risk by a specified factor of $k$, then the answer is as follows: $\mathrm{n}_{\mathrm{k}}$ is the smallest integer at least as large as $k$ raised to the power 1/0.309. In mathematical notation,

$$
n_{k}=k^{\alpha /(\alpha-1)}+1 \approx k^{3.23}+1
$$

This implies that the number of properties in a portfolio needed to achieve a four-fold reduction in the magnitude of combined asset-specific risk is 88 - compared with only 16 properties if asset-specific risk were normally distributed. Similarly, the number of properties in a portfolio needed to achieve a ten-fold reduction in combined asset-specific risk is 1,698 - compared with 100 properties if asset-specific risk were normally distributed. In other words, if purchases are restricted to institutional-grade properties, equally weighted investments in one-sixth of the properties currently in the IPD U.K. database would be needed to achieve a ten-fold reduction in the magnitude of combined asset-specific risk 6 .

The effect of varying $\alpha$ upon the portfolio size needed to achieve risk reduction by various specified factors $k$ is shown in Figure 13.

$6 \quad$ These results may further explain why the observed volatility and tracking error of large portfolios is greater than generally expected, in addition to previously offered reasons of active management, uneven lot sizes and property investments being mutually exclusive (see Cullen, 1991; Morrell, 1993, 1997; Schuck and Brown, 1997). 


\section{Conclusions}

The empirical results in this study support the existing real estate literature in emphasizing that it is unsafe to assume normality of property returns. For the IPD U.K. annual data, normality was emphatically rejected.

When sub-sector returns were analyzed, normality was rejected in almost all cases. Individual (continuously compounded) annual property returns in the IPD database are not normally distributed for calendar years during the period 1981-2003, with only two exceptions each for office and retail properties.

For each calendar year $t$ in that interval, there is a stable infinite-variance distribution with characteristic exponent $\alpha_{\mathrm{t}}$ such that the return on each property for year $t$ can be represented as the average (mean) return for that year on properties of the same commercial type plus a random sample from the stable distribution for that year, and furthermore that these samples are independent for distinct properties or calendar years. These stable distributions can be considered to represent real estate asset-specific risk.

The data analysis strongly implies that both the skewness and magnitude of real estate asset-specific risk change over time, i.e., real estate risk is heteroskedastic with respect to both the amount of risk and the shape of the risk distribution. There are also some variations in parameters between property types, which may be worth future research, along with exploration of which properties fall within the tail regions of the distributions in particular years.

However, the analysis also supports the conclusion that there is a single value for the characteristic exponent of asset-specific risk across both calendar year and property type. A statistical estimate of this common value for the characteristic exponent $\alpha_{\mathrm{t}}$ together with a $95 \%$ confidence interval around this value is $1.448 \pm 0.004$, based on a sample distribution of 269,853 annual property returns over the twenty-three-year sample period. This interval is so far from 2.0 - the value for a normal distribution - that it has profound implications 
for real estate portfolio management. In particular, the degree to which portfolio-level risk can be reduced by the inclusion of more real estate assets is dramatically overstated in models that presume a normal distribution of asset returns.

Because real estate investment risk has infinite variance, there is no way to measure codependence among property risk functions with the statistical tools currently available. In particular, sample correlations used in multi-factor MPT real estate risk models are fictitious products of flawed data analysis methodology, and do not measure true risk codependence.

The fact that the distribution of property returns appears to behave in a different way from those of equities and bonds has implications for asset allocation models based on the standard deviation (or variance) as the measure of risk. The inclusion of real estate returns, especially when measured over small intervals, alongside other asset classes in optimizing procedures may produce misleading results. Consequently, Byrne and Lee (1997) and Coleman and Mansour (2005) recommend alternatives to mean-variance analysis. Byrne and Lee (1997) advocate Mean Absolute Deviation (MAD) optimization, which is less sensitive to departures from normality, yet produces portfolio compositions similar to meanvariance analysis (see also Byrne and Lee, 2005). Coleman and Mansour (2005) suggest the use of more flexible statistical distributions to account for the skewness and leptokurtic nature of real estate returns in the optimization process.

A final observation concerns the accuracy of appraisal-based returns data relative to transaction-based data. The fact that thousands of appraisals by real estate professionals across the country over a twenty-three-year period form sample distributions with nearly indistinguishable characteristic exponents across calendar years by property types suggests strongly that the real estate community has a common perception of asset value and the sources of that value that have remained constant across changing market regimes of liquidity, credit access, and supply and demand of product. 


\section{References}

Booth, P.M., Matysiak, G.A. and Ormerod, P. (2002) Risk Measurement and Management for Real Estate Investment Portfolios, Summary Report, commissioned by the Investment Property Forum and funded by the Investment Property Forum Educational Trust, London.

Brown, G.R. (1991) Property Investment and the Capital Markets, Chapman \& Hall, London.

Brown, G.R. and Matysiak, G.A. (2000) Real Estate Investment: A Capital Market Approach, Financial Times Prentice Hall, Harlow.

Byrne P.J. and Lee, S.L. (1997) Real Estate Portfolio Analysis Under Conditions of NonNormality: The Case of NCREIF, Journal of Real Estate Portfolio Management, 3(1), $37-46$.

Byrne, P.J. and Lee, S.L. (2005) Different Risk Measures: Different Portfolio Compositions? Journal of Property Investment and Finance, 22(6), 501-511.

Coleman M.S. and Mansour, A. (2005) Real Estate in the Real World: Dealing with NonNormality and Risk in an Asset Allocation Model, Journal of Real Estate Portfolio Management, 11(1), 37-54.

Cullen, I. (1991) Risk Management in Investment Property Portfolios, Presented as part of the seminar series 'Property in a Portfolio Context', organized by the Society of Property Researchers and the RICS.

Fama, E.F. (1965a) The Behavior of Stock Market Prices, Journal of Business, 38(1), 34105.

Fama, E.F. (1965b) Portfolio Analysis in a Stable Paretian Market, Management Science, $11,404-419$. 
Fama, E.F. and Miller, M.H. (1972) The Theory of Finance, Holt, Rinehart and Winston, New York.

Graff R.A., Harrington, A. and Young, M.S. (1997) The Shape of Australian Real Estate Return Distributions and Comparisons to the United States, Journal of Real Estate Research, 14(3), 291-308.

IPD (2005) IPD UK Annual Index, Investment Property Databank, London.

Lee, S.L. (2002) Volatility Persistence and Time-Varying Betas in the U.K. Real Estate Market, Working Papers in Real Estate \& Planning 05/02, University of Reading.

Lizieri, C.M. and Ward, C.W.R. (2000) Commercial Real Estate Return Distributions: A Review of the Literature and Empirical Evidence, in Return Distributions in Finance (edited by J. Knight and S. Satchell), Butterworth Heinemann, Oxford, pp 47-74.

Maurer, R., Reiner, F. and Sebastian, S. (2004) Characteristics of German Real Estate Return Distributions: Evidence from Germany and Comparisons to the U.S. and U.K., Journal of Real Estate Portfolio Management, 10(1), 59-76.

McCulloch, J.H. (1975) An Estimate of the Liquidity Premium, Journal of Political Economy, 83, 95-119.

McCulloch, J.H. (1978) Continuous Time Processes with Stable Increments, Journal of Business, 51, 601-619.

McCulloch, J.H. (1986) Simple Consistent Estimators of Stable Distribution Parameters, Communications in Statistics: Simulation and Computation, 15, 1109-1136.

Morrell, G. D. (1993) Value Weighting and the Variability of Real Estate Returns: Implications for Portfolio Construction and Performance Evaluation, Journal of Property Research, 10, 167-183.

Morrell, G. D. (1997) Property Risk and Portfolio Construction, Presented to the Sixth IPD Investment Strategies Conference, Brighton, 27-28 November 1997. 
Myer, F.C.N. and Webb, J.R. (1994) Statistical Properties of Returns: Financial Assets versus Commercial Real Estate, Journal of Real Estate Finance and Economics, 8(3), 267-282.

Schuck, E. J. and Brown, G. R. (1997) Value Weighting and Real Estate Portfolio Risk, Journal of Property Research, 14 (3), 169-187.

Young, M.S. and Graff, R.A. (1995) Real Estate Is Not Normal: A Fresh Look at Real Estate Return Distributions, Journal of Real Estate Finance and Economics, 10(3), 225259.

Young, M.S. (2005) Non-Normal Real Estate Return Distributions by Property Type in the U.S., Paper presented at ARES Annual Meeting, Santa Fe, New Mexico. 
Figure 1a

Distribution of Log Annual Total Return Residuals

IPD, All Properties, 1981 to 2003

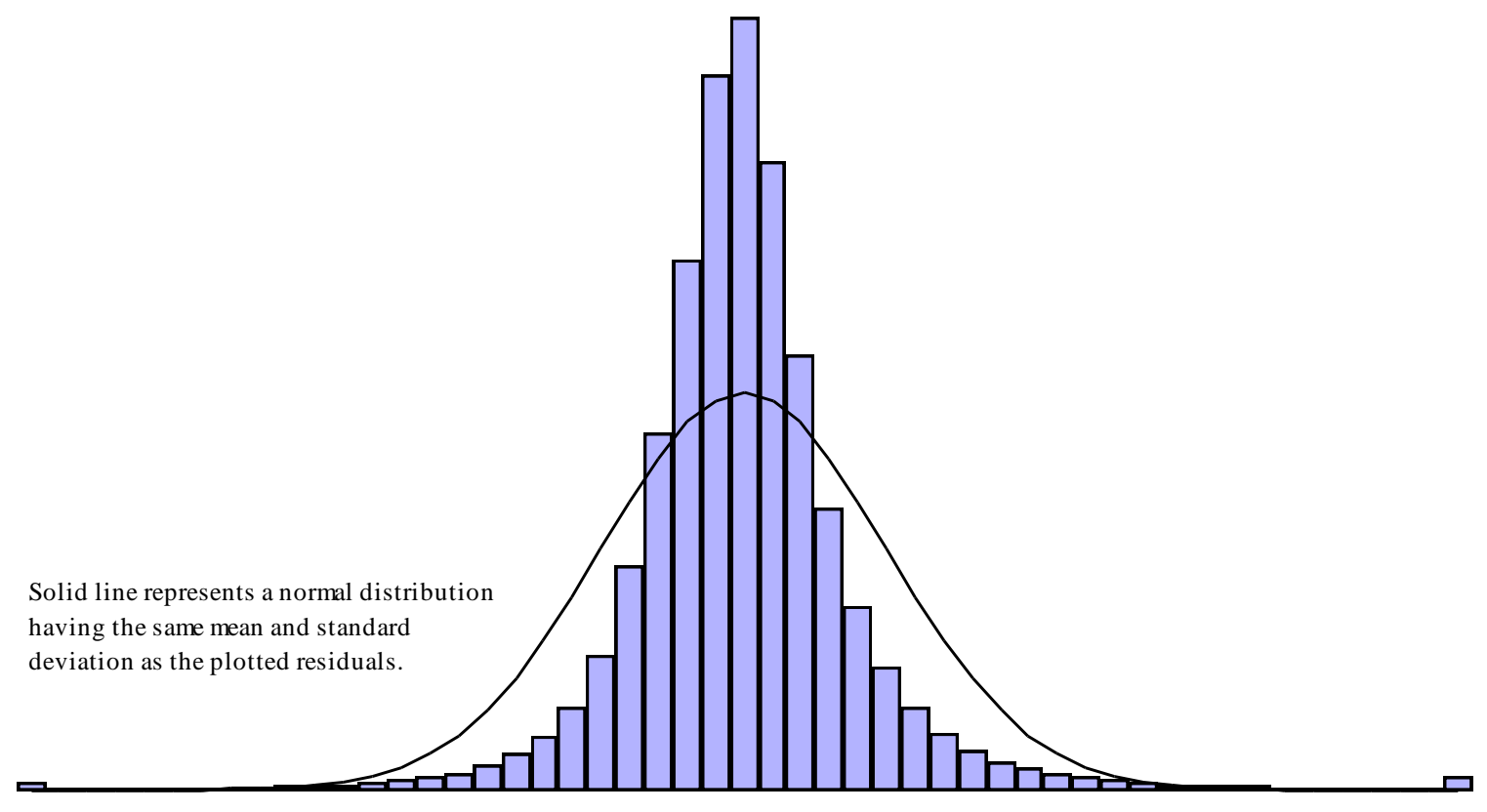

Figure 1b

Difference in Frequency, Log Annual Total Return Residuals to Normal Distribution

IPD, All Properties, 1981 to 2003

Samples greater than or less than 5 standard deviations from the mean have been placed in the extreme bins.

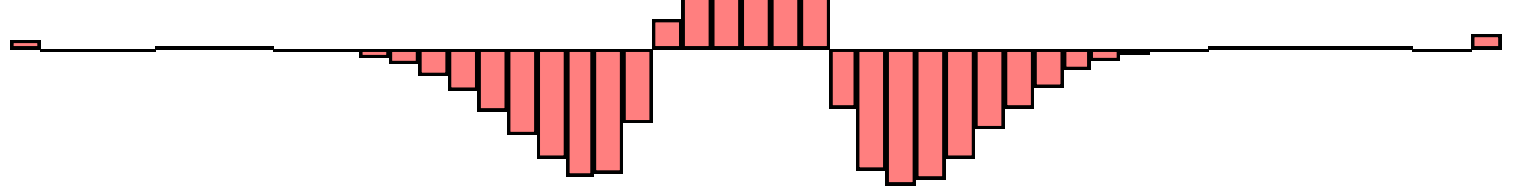


Figure 2a

Distribution of Log Annual Total Return Residuals

IPD, Office Properties, 1981 to 2003

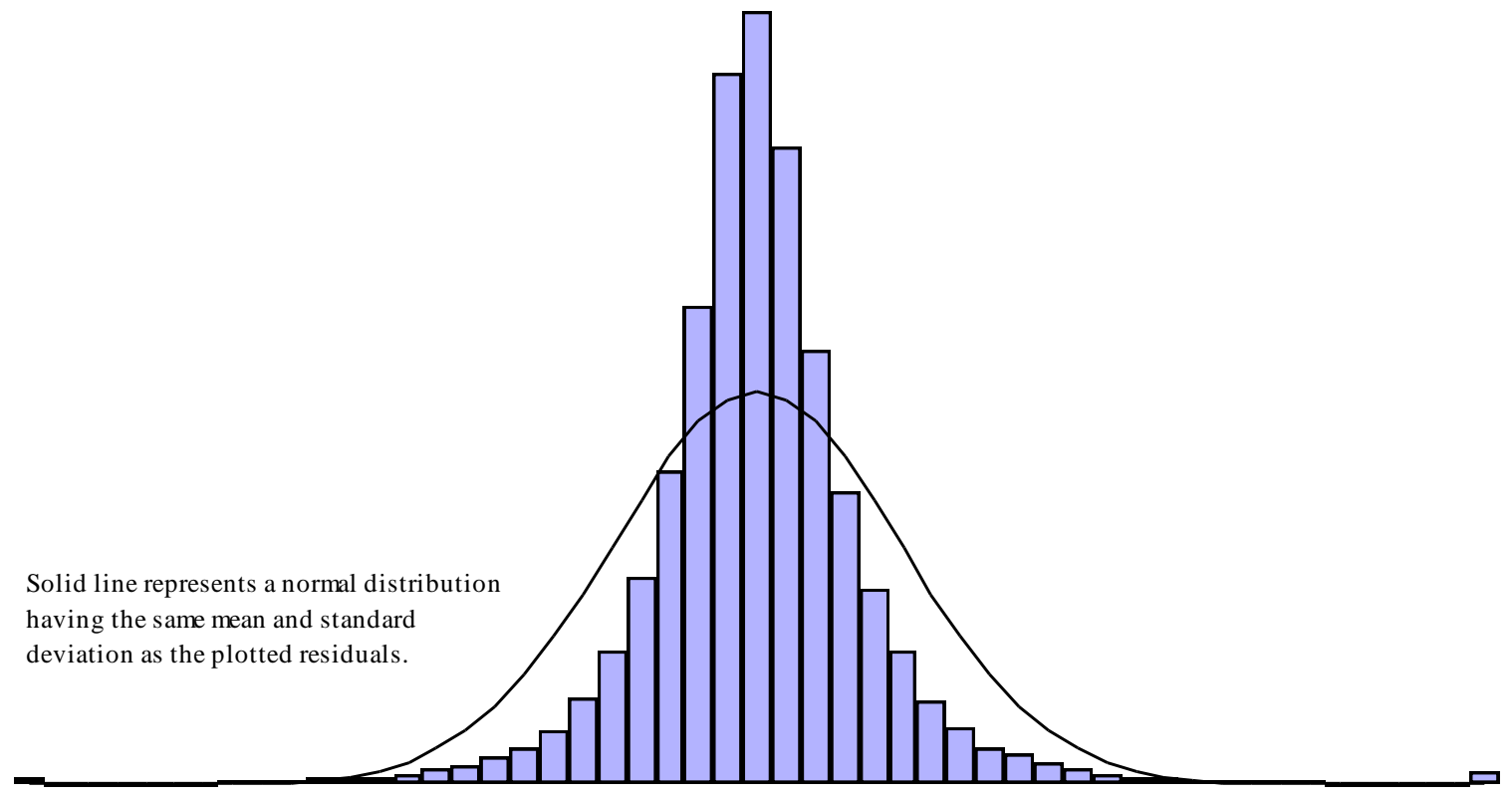

Figure $2 b$

Difference in Frequency, Log Annual Total Return Residuals to Normal Distribution

IPD, Office Properties, 1981 to 2003

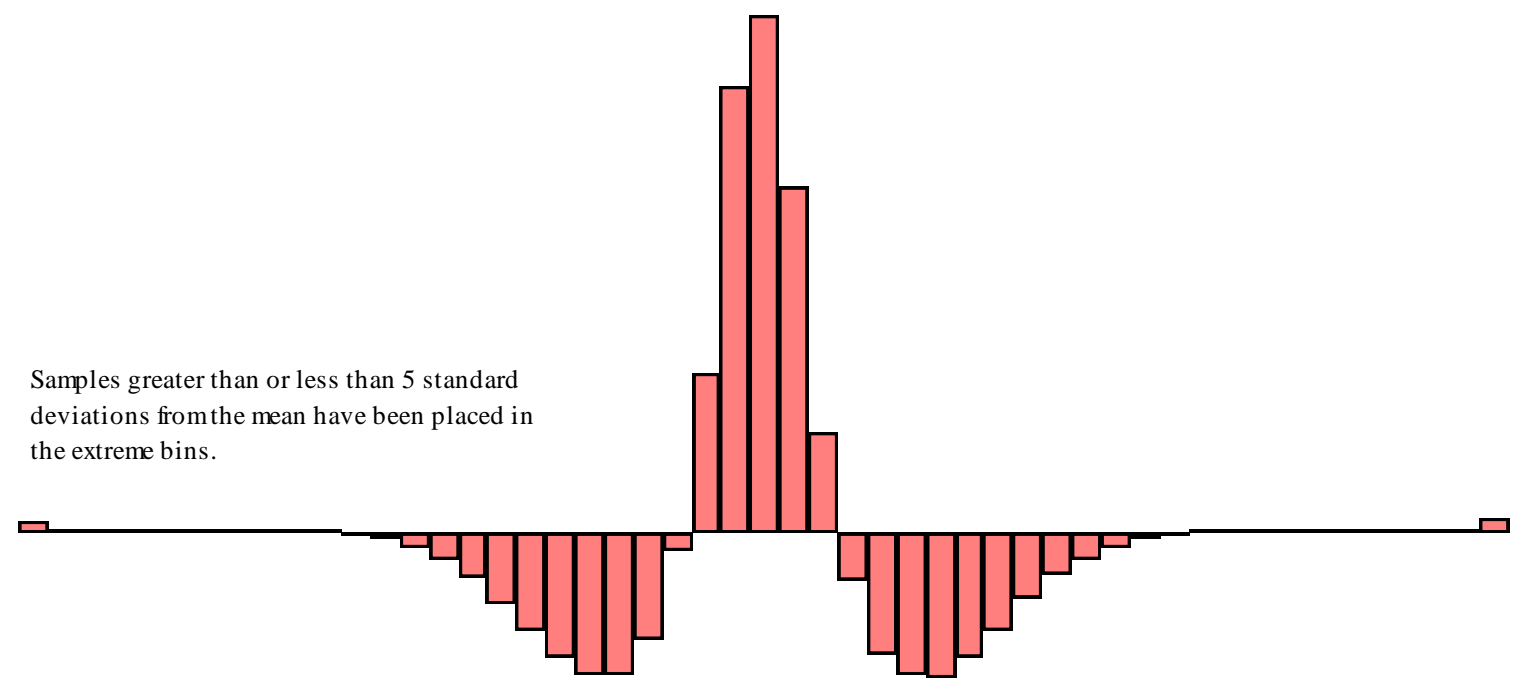


Figure 3a

Distribution of Log Annual Total Return Residuals

IPD, Retail Properties, 1981 to 2003

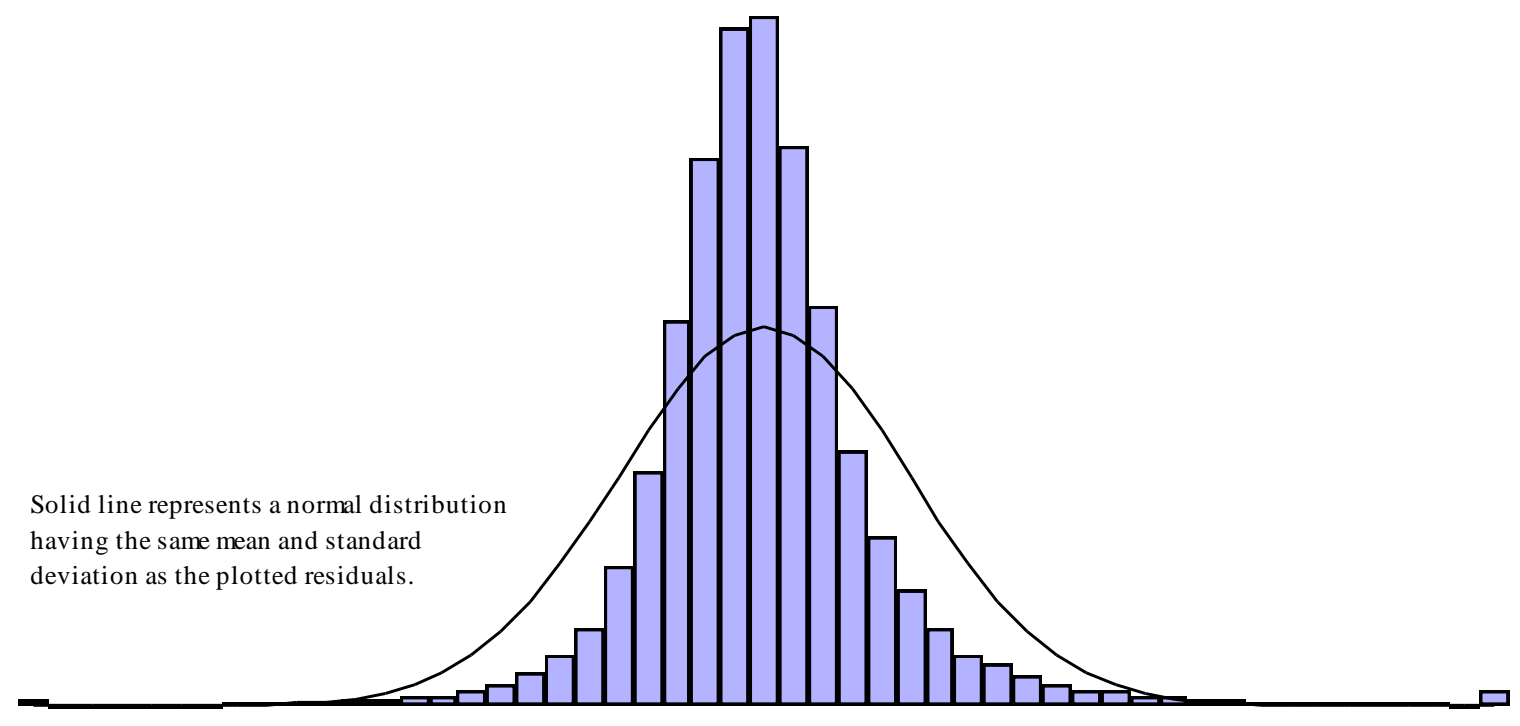

Figure $3 b$

Difference in Frequency, Log Annual Total Return Residuals to Normal Distribution

IPD, Retail Properties, 1981 to 2003

Samples greater than or less than 5 standard deviations from the mean have been placed in the extreme bins.

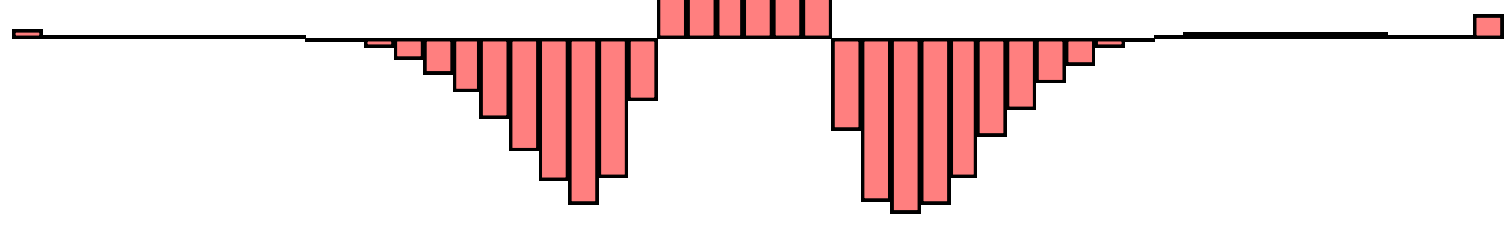


Figure 4a

Distribution of Log Annual Total Return Residuals

IPD, Industrial Properties, 1981 to 2003

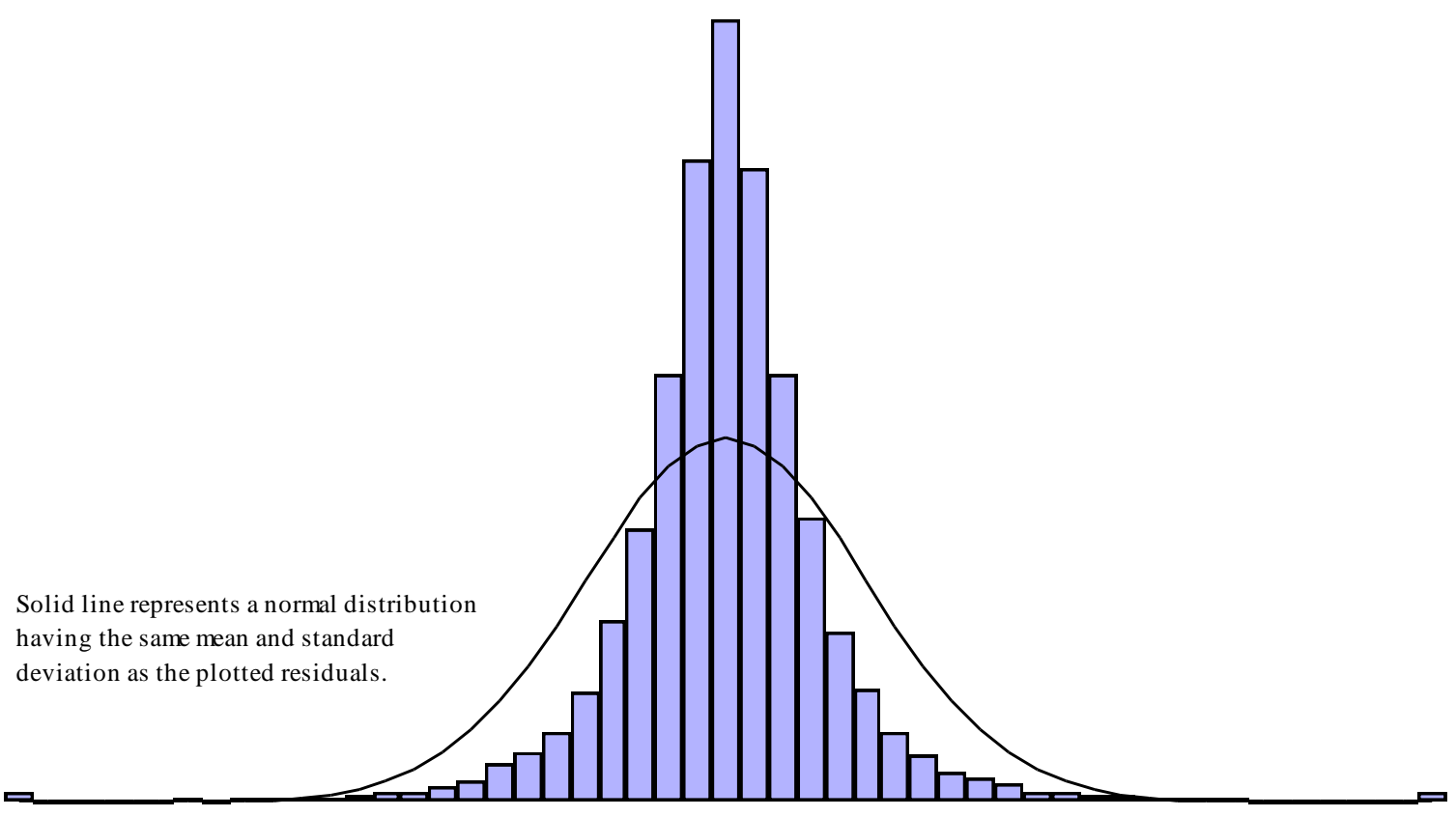

Figure $4 b$

Difference in Frequency, Log Annual Total Return Residuals to Normal Distribution IPD, Industrial Properties, 1981 to 2003

Samples greater than or less than 5 standard deviations from the mean have been placed in the extreme bins.

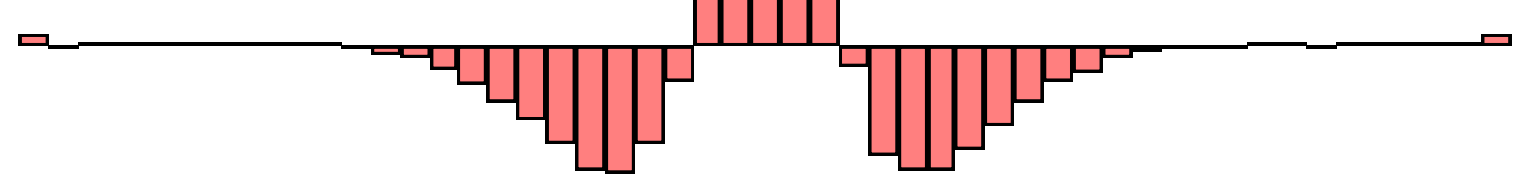


Figure 5

Stable Distribution Parameters for IPD Property Database

Log Annual Total Return Residuals \& Mean Returns \& Number of Properties

All Properties Combined:

\begin{tabular}{llllrc}
$\begin{array}{l}\text { Year or } \\
\text { Period }\end{array}$ & $\alpha$ & $\beta$ & $\gamma$ & $\begin{array}{r}\text { Mean } \\
\text { Return }\end{array}$ & $\begin{array}{c}\text { Number of } \\
\text { Properties }\end{array}$ \\
\hline 2003 & $1.423 * *$ & -0.026 & 0.046 & 0.107 & 9,133 \\
2002 & $1.417 * *$ & $-0.089 * *$ & 0.047 & 0.096 & 9,787 \\
2001 & $1.433 * *$ & 0.004 & 0.047 & 0.068 & 10,413 \\
2000 & $1.446 * *$ & $0.123 * *$ & 0.052 & 0.083 & 11,361 \\
1999 & $1.440 * *$ & $0.300 * *$ & 0.049 & 0.129 & 11,796 \\
1998 & $1.414 * *$ & $0.148 * *$ & 0.049 & 0.102 & 12,600 \\
1997 & $1.409 * *$ & $0.261 * *$ & 0.056 & 0.132 & 12,642 \\
1996 & $1.322 * *$ & -0.007 & 0.043 & 0.080 & 12,983 \\
1995 & $1.469 * *$ & $-0.282 * *$ & 0.056 & 0.020 & 13,356 \\
1994 & $1.459 * *$ & $-0.177 * *$ & 0.064 & 0.094 & 12,789 \\
1993 & $1.517 * *$ & $-0.265 * *$ & 0.087 & 0.165 & 12,363 \\
1992 & $1.527 * *$ & $-0.596 * *$ & 0.079 & -0.013 & 12,428 \\
1991 & $1.500 * *$ & $-0.248 * *$ & 0.081 & 0.015 & 11,892 \\
1990 & $1.632 * *$ & -0.011 & 0.088 & -0.067 & 11,309 \\
1989 & $1.597 * *$ & $0.602 * *$ & 0.088 & 0.157 & 11,126 \\
1988 & $1.743 * *$ & $1.000 * *$ & 0.099 & 0.274 & 11,493 \\
1987 & $1.615 * *$ & $1.000 * *$ & 0.086 & 0.207 & 12,123 \\
1986 & $1.434 * *$ & $0.344 * *$ & 0.068 & 0.123 & 12,341 \\
1985 & $1.461 * *$ & $0.344 * *$ & 0.066 & 0.107 & 12,042 \\
1984 & $1.349 * *$ & $0.399 * *$ & 0.063 & 0.127 & 11,853 \\
1983 & $1.338 * *$ & $0.305 * *$ & 0.060 & 0.116 & 11,539 \\
1982 & $1.324 * *$ & $0.428 * *$ & 0.064 & 0.114 & 11,475 \\
1981 & $1.283 * *$ & $0.537 * *$ & 0.069 & 0.173 & 11,009 \\
\hline $1981-03$ & $1.448 * *$ & $0.136 * *$ & 0.066 & 0.104 & 269,853 \\
\hline & & & & &
\end{tabular}


Figure 5 (continued)

Stable Distribution Parameters for IPD Property Database

Log Annual Total Return Residuals \& Mean Returns \& Number of Properties

Office Properties:

\begin{tabular}{llcccc}
$\begin{array}{l}\text { Year or } \\
\text { Period }\end{array}$ & $\alpha$ & $\beta$ & $\gamma$ & $\begin{array}{c}\text { Mean } \\
\text { Return }\end{array}$ & $\begin{array}{c}\text { Number of } \\
\text { Properties }\end{array}$ \\
\hline 2003 & $1.441 * *$ & $-0.371 * *$ & 0.055 & 0.041 & 2,551 \\
2002 & $1.504 * *$ & $-0.321 * *$ & 0.059 & 0.045 & 2,849 \\
2001 & $1.390 * *$ & $0.098 *$ & 0.047 & 0.081 & 2,987 \\
2000 & $1.370 * *$ & $0.379 * *$ & 0.052 & 0.130 & 3,075 \\
1999 & $1.422 * *$ & $0.333 * *$ & 0.052 & 0.140 & 3,216 \\
1998 & $1.394 * *$ & $0.175 * *$ & 0.054 & 0.113 & 3,479 \\
1997 & $1.309 * *$ & $0.242 * *$ & 0.056 & 0.131 & 3,564 \\
1996 & $1.271 * *$ & $-0.262 * *$ & 0.045 & 0.063 & 3,783 \\
1995 & $1.389 * *$ & $-0.319 * *$ & 0.061 & 0.016 & 3,963 \\
1994 & $1.406 * *$ & $-0.270 * *$ & 0.068 & 0.083 & 3,917 \\
1993 & $1.541 * *$ & $-0.739 * *$ & 0.110 & 0.129 & 3,803 \\
1992 & $1.551 * *$ & $-1.000 * *$ & 0.101 & -0.094 & 3,830 \\
1991 & $1.644 * *$ & $-0.781 * *$ & 0.111 & -0.072 & 3,752 \\
1990 & $1.645 * *$ & $-0.121 *$ & 0.096 & -0.080 & 3,576 \\
1989 & $1.692 * *$ & $0.829 * *$ & 0.099 & 0.198 & 3,456 \\
1988 & $1.750 * *$ & $1.000 * *$ & 0.106 & 0.293 & 3,531 \\
1987 & $1.706 * *$ & $1.000 * *$ & 0.104 & 0.221 & 3,765 \\
1986 & $1.476 * *$ & $0.172 * *$ & 0.076 & 0.096 & 3,892 \\
1985 & $1.357 * *$ & $0.167 * *$ & 0.060 & 0.088 & 3,823 \\
1984 & $1.273 * *$ & $0.105 * *$ & 0.055 & 0.094 & 3,725 \\
1983 & $1.275 * *$ & $0.114 * *$ & 0.050 & 0.087 & 3,616 \\
1982 & $1.318 * *$ & $0.337 * *$ & 0.058 & 0.102 & 3,595 \\
1981 & $1.366 * *$ & $0.495 * *$ & 0.066 & 0.158 & 3,373 \\
\hline $1981-03$ & $1.431 * *$ & $0.053 * *$ & 0.072 & 0.089 & 81,121 \\
\hline & & & & &
\end{tabular}


Figure 5 (continued)

Stable Distribution Parameters for IPD Property Database

Log Annual Total Return Residuals \& Mean Returns \& Number of Properties

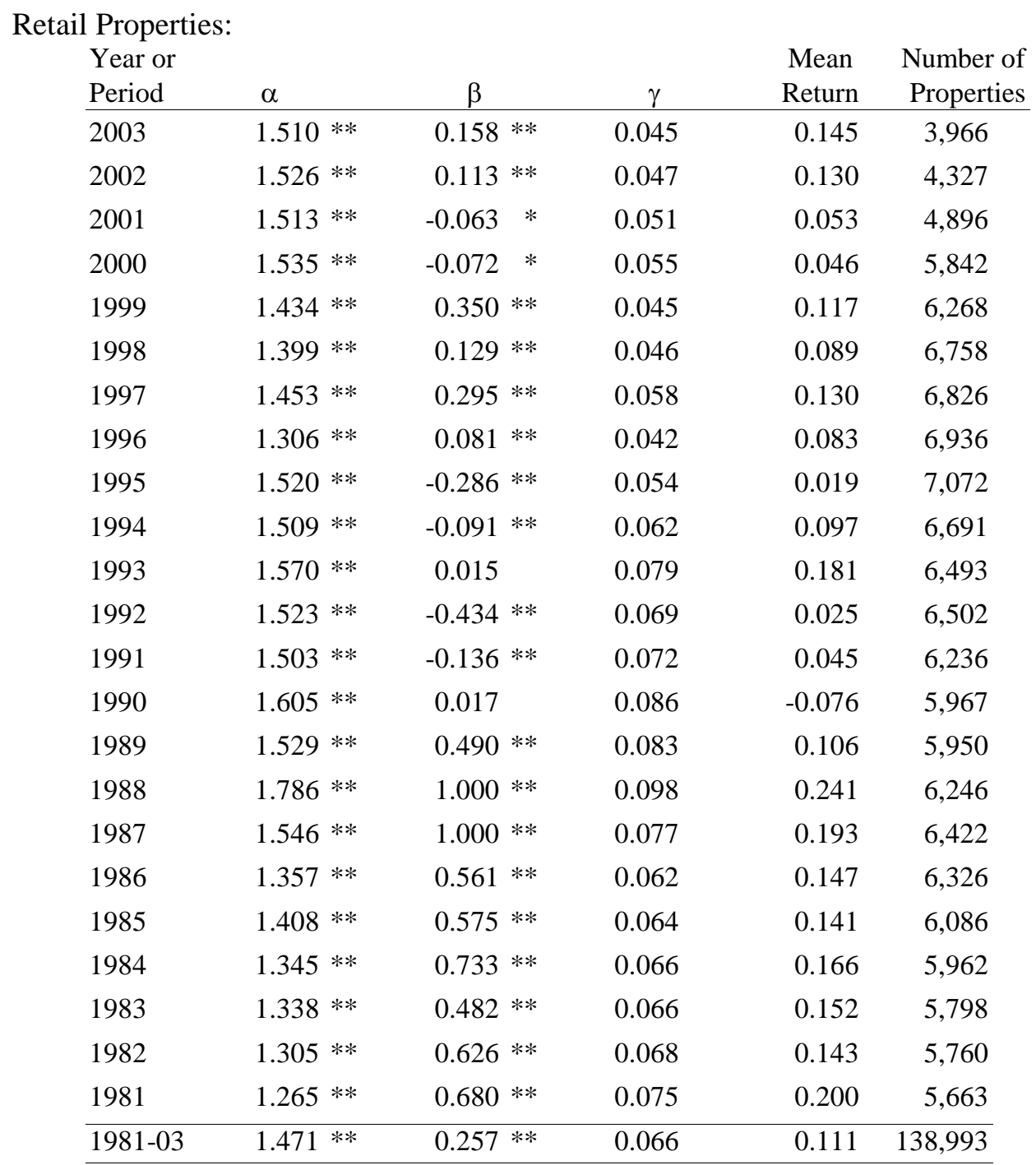


Figure 5 (continued)

Stable Distribution Parameters for IPD Property Database

Log Annual Total Return Residuals \& Mean Returns \& Number of Properties

Industrial Properties:

\begin{tabular}{llcccc}
$\begin{array}{l}\text { Year or } \\
\text { Period }\end{array}$ & $\alpha$ & $\beta$ & $\gamma$ & $\begin{array}{c}\text { Mean } \\
\text { Return }\end{array}$ & $\begin{array}{c}\text { Number of } \\
\text { Properties }\end{array}$ \\
\hline 2003 & $1.324 * *$ & $0.094 *$ & 0.038 & 0.112 & 2,616 \\
2002 & $1.215 * *$ & $-0.074 *$ & 0.032 & 0.094 & 2,661 \\
2001 & $1.311 * *$ & 0.024 & 0.036 & 0.083 & 2,530 \\
2000 & $1.369 * *$ & $0.090 *$ & 0.043 & 0.114 & 2,444 \\
1999 & $1.488 * *$ & $0.198 * *$ & 0.054 & 0.147 & 2,312 \\
1998 & $1.472 * *$ & $0.119 *$ & 0.048 & 0.120 & 2,363 \\
1997 & $1.508 *$ & $0.258 * *$ & 0.050 & 0.143 & 2,252 \\
1996 & $1.280 * *$ & $0.080 *$ & 0.036 & 0.098 & 2,264 \\
1995 & $1.549 * *$ & $-0.335 * *$ & 0.057 & 0.028 & 2,321 \\
1994 & $1.458 * *$ & $-0.114 *$ & 0.063 & 0.105 & 2,181 \\
1993 & $1.581 * *$ & $-0.458 * *$ & 0.080 & 0.181 & 2,067 \\
1992 & $1.591 * *$ & $-0.951 * *$ & 0.070 & 0.018 & 2,096 \\
1991 & $1.527 * *$ & $-0.161 *$ & 0.063 & 0.090 & 1,904 \\
1990 & $1.610 * *$ & 0.003 & 0.077 & -0.013 & 1,766 \\
1989 & $1.698 * *$ & $0.914 * *$ & 0.087 & 0.248 & 1,720 \\
1988 & $1.772 * *$ & $1.000 * *$ & 0.098 & 0.354 & 1,716 \\
1987 & $1.854 * *$ & $1.000 * *$ & 0.087 & 0.228 & 1,936 \\
1986 & $1.448 * *$ & $-0.080 *$ & 0.058 & 0.102 & 2,123 \\
1985 & $1.679 * *$ & $-0.227 *$ & 0.072 & 0.045 & 2,133 \\
1984 & $1.426 * *$ & -0.060 & 0.056 & 0.074 & 2,166 \\
1983 & $1.428 * *$ & -0.041 & 0.052 & 0.064 & 2,125 \\
1982 & $1.344 * *$ & $-0.132 *$ & 0.051 & 0.055 & 2,120 \\
1981 & $1.234 * *$ & $0.220 * *$ & 0.050 & 0.123 & 1,973 \\
\hline $1981-03$ & $1.425 * *$ & $-0.025 *$ & 0.056 & 0.110 & 49,739 \\
\hline & & & & &
\end{tabular}

Statistically significant confidence of non-normality $\alpha \neq 2.0)$ or skewness $(\beta \neq 0)$ :

$* *=99 \%$ confidence

$*=95 \%$ confidence

$\alpha \square$ is the characteristic exponent, and only equals 2.0 for the normal distribution

$\beta$ is the skewness parameter in the range -1.0 to +1.0

$\gamma$ is the (positive) scale parameter which measures the spread of the distribution about $\delta$

Note: The means are shown in Figure 5 for purposes of completeness, but will not be needed for discussion or analysis in the body of this article. 
Figure 6

Characteristic Exponent "Alpha" of Distributions of Log Annual Total Return Residuals

IPD 1981 to 2003

(bands indicate plus and minus one and two standard deviations)
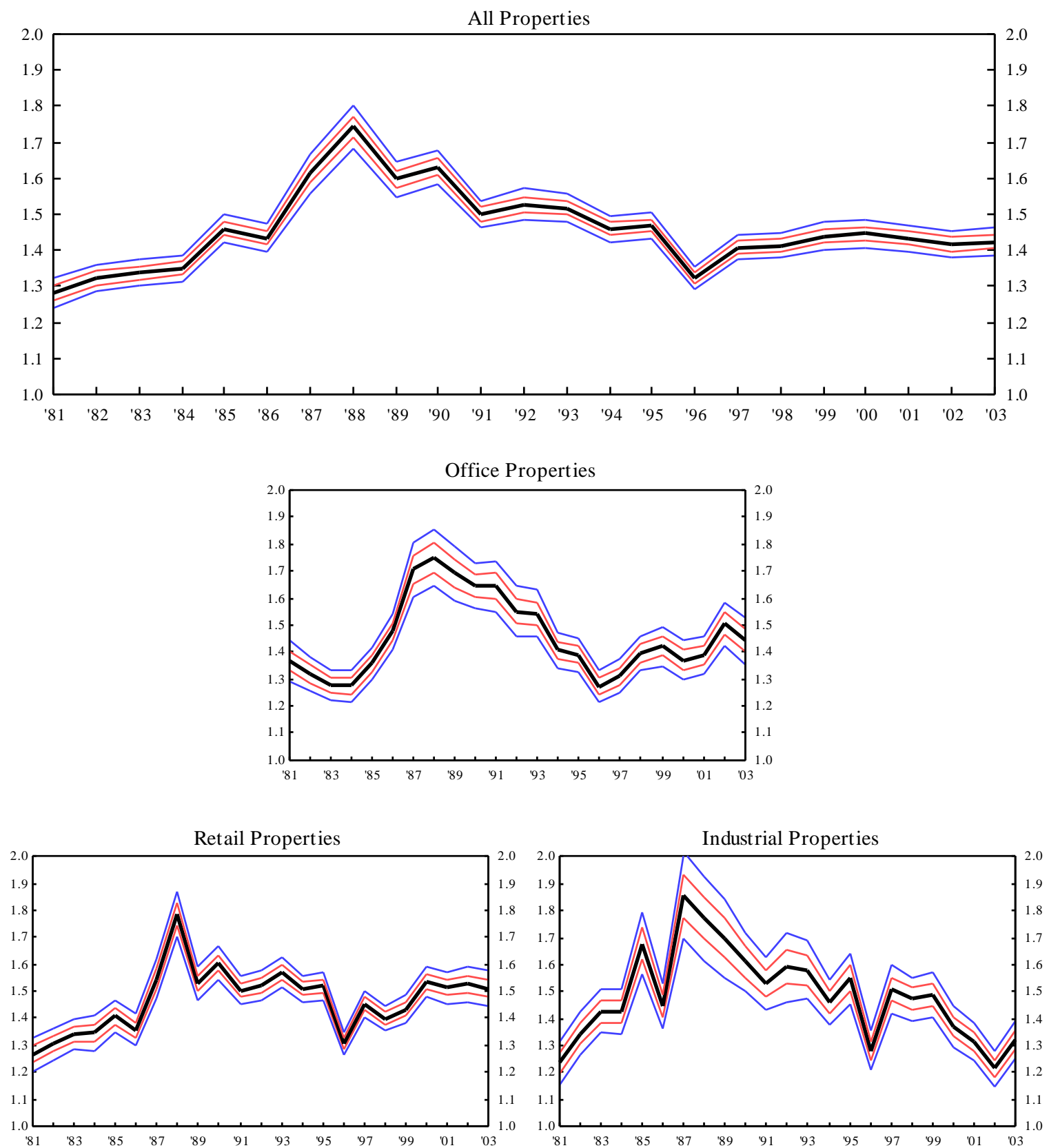
Figure 7

Skewness Parameter "Beta" of Distributions of Log Annual Total Return Residuals IPD 1981 to 2003

(bands indicate plus and minus one and two standard deviations)

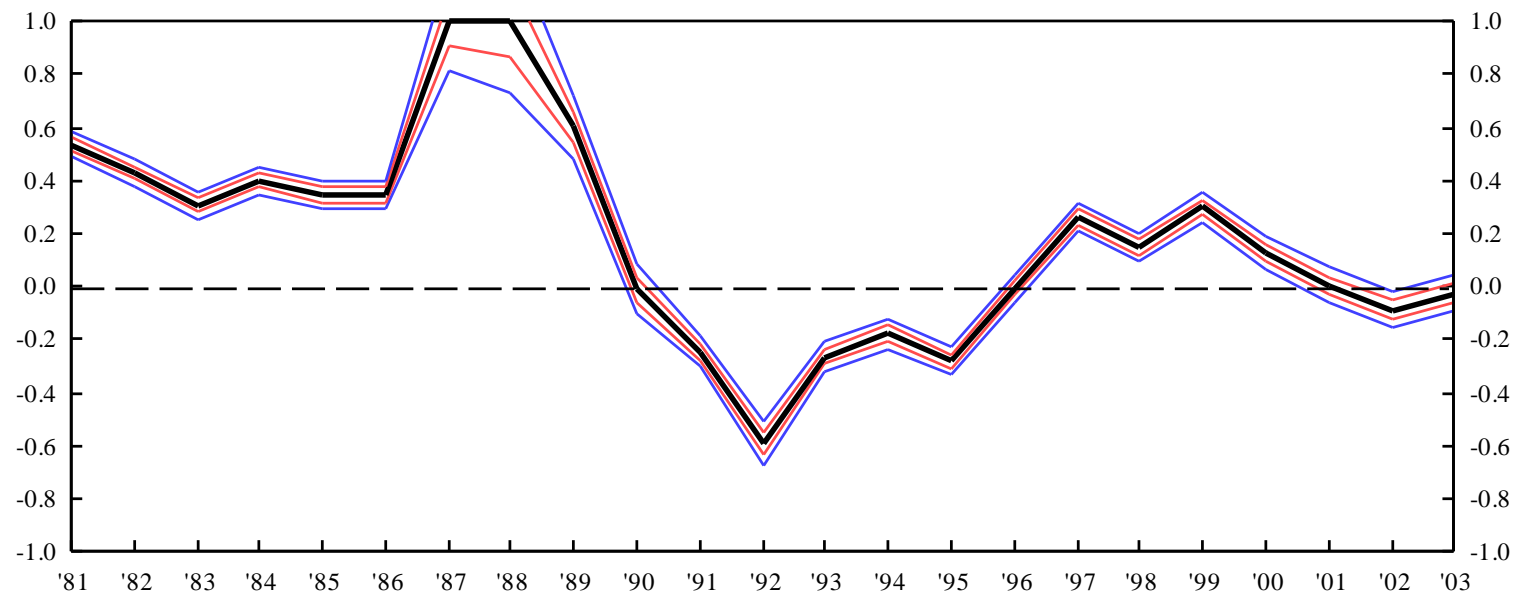

Office Properties
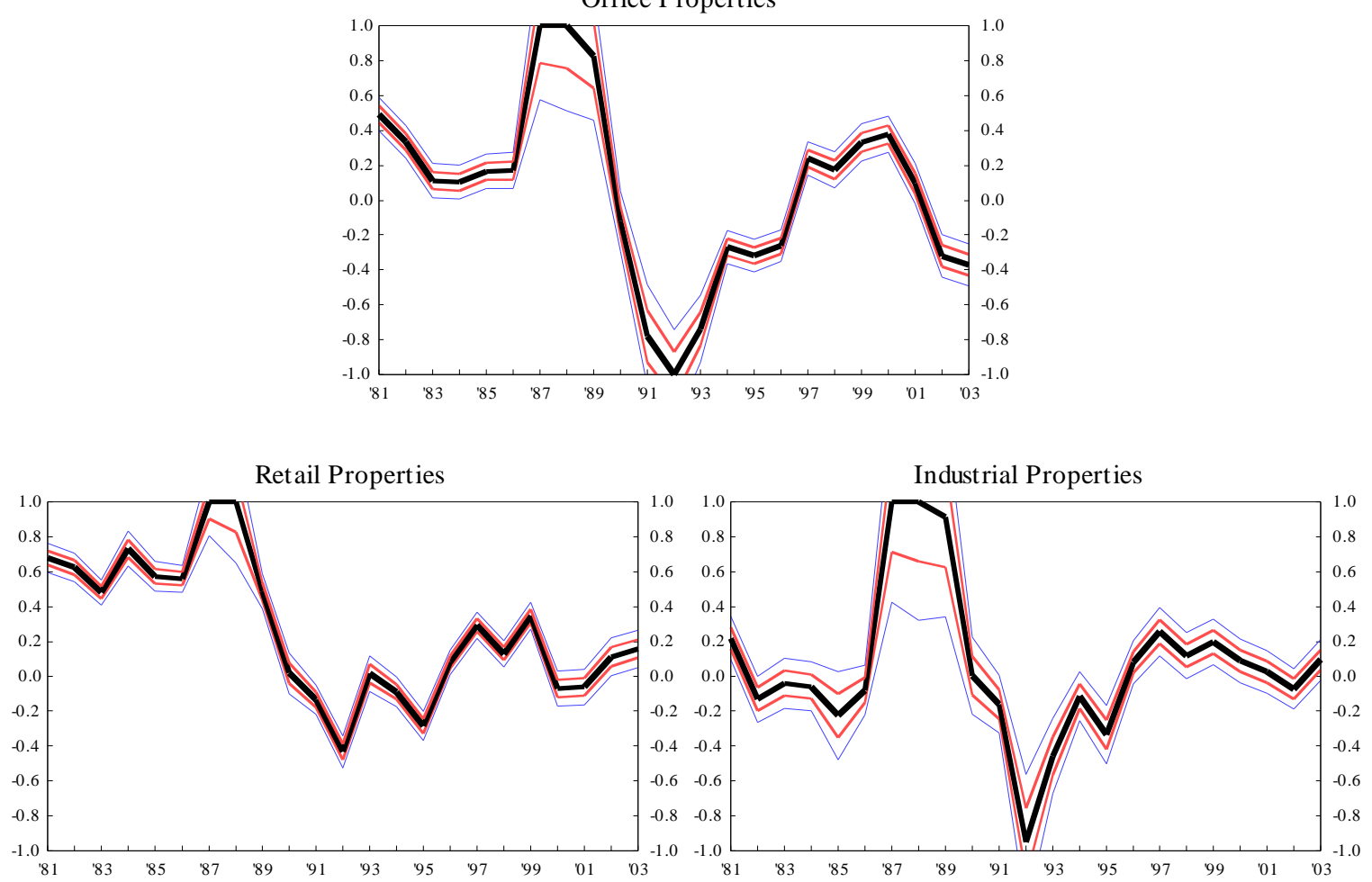
Figure 8

Scale Parameter "Gamma" of Distributions of Log Annual Total Return Residuals

IPD 1981 to 2003

(bands indicate plus and minus one and two standard deviations)
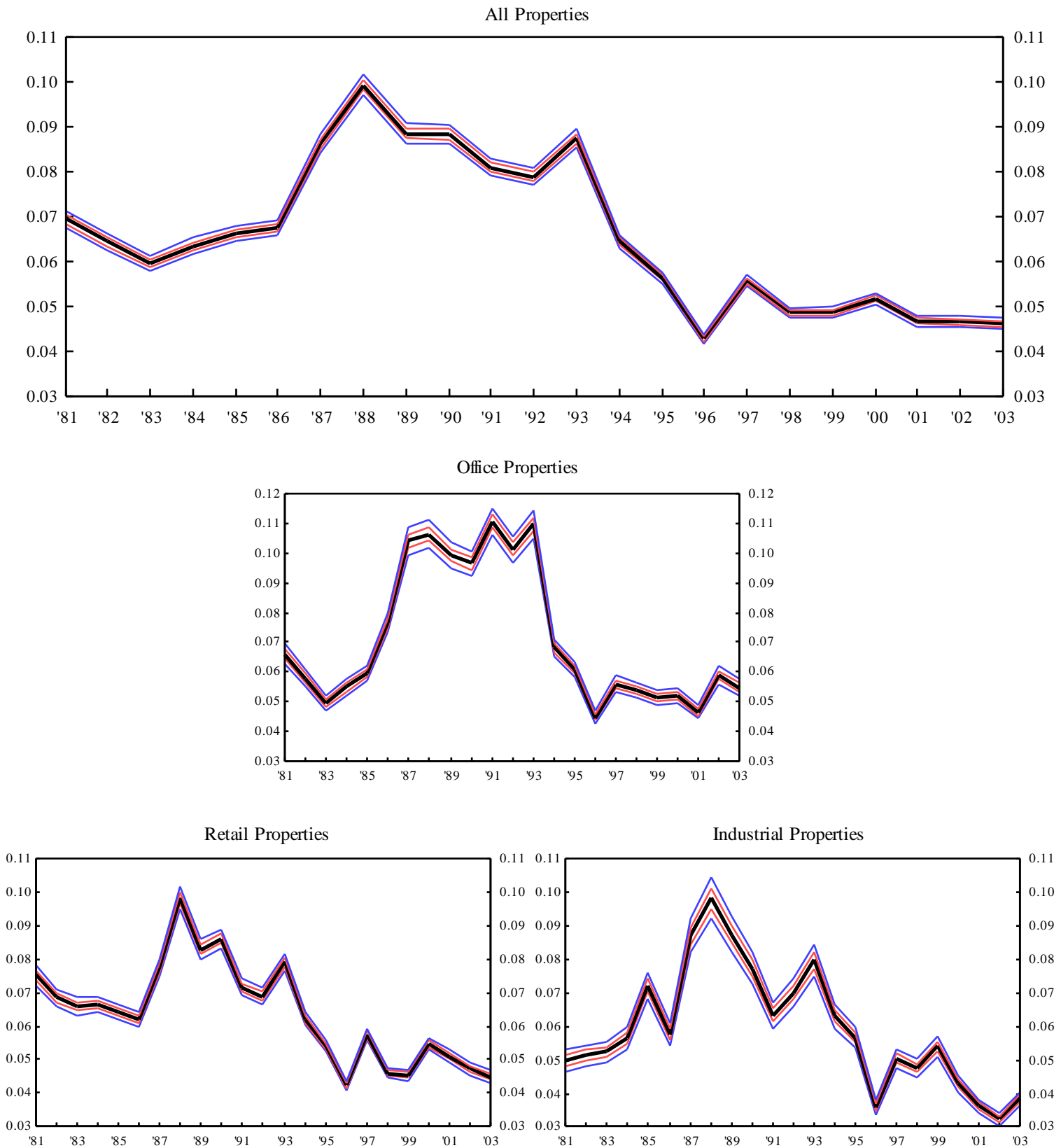
Figure 9

Three Parameters of Distributions of Log Annual Total Return Residuals by Property Type IPD 1981 to 2003

(bands indicate plus and minus one and two standard deviations)
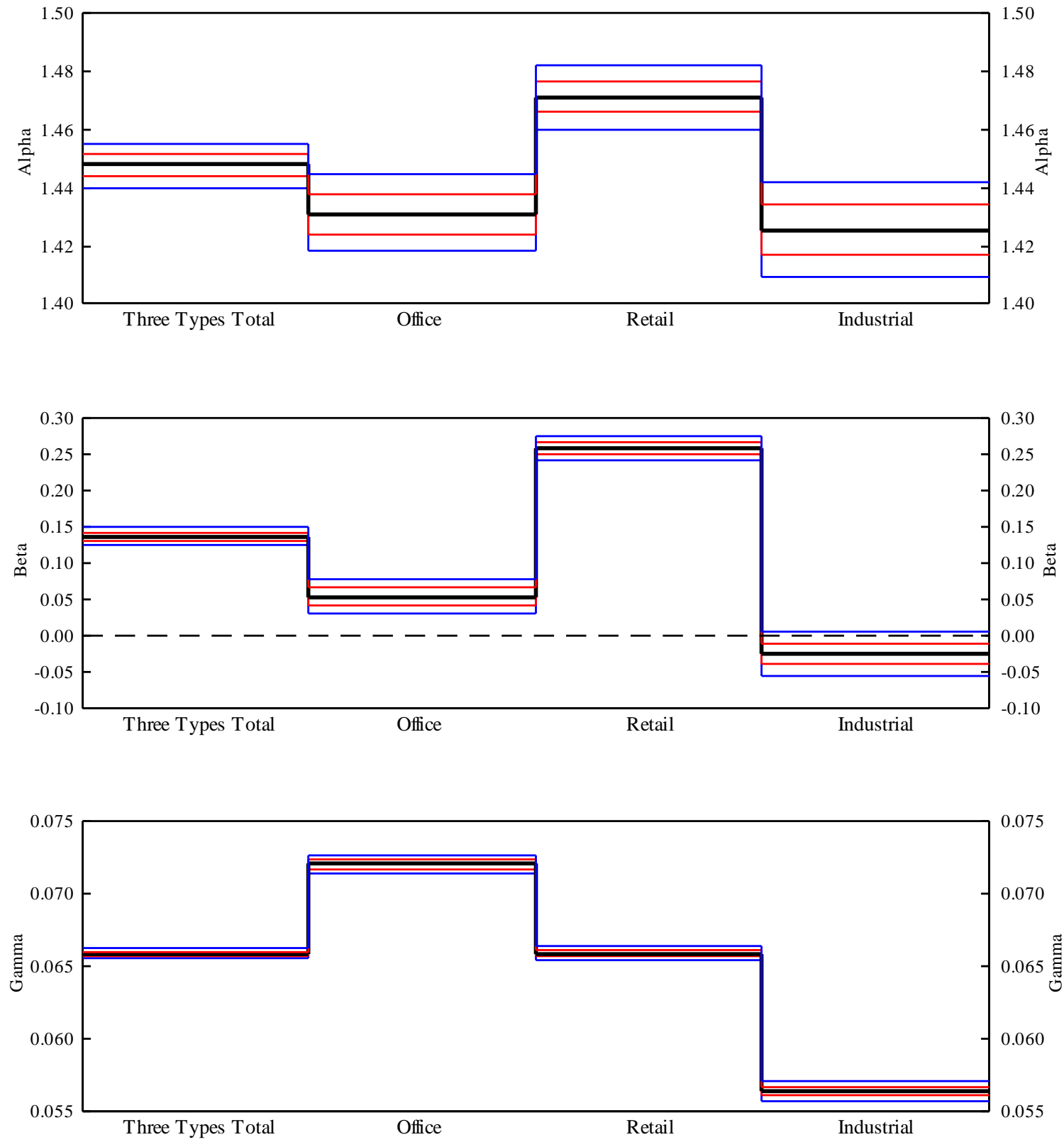
Figure 10

Characteristic Exponent $\alpha$ for IPD Property Database

Log Annual Total Return Residual Distributions

All Properties, Properties by Type, and Chi-square Goodness of Fit Results

\begin{tabular}{|c|c|c|c|c|c|c|}
\hline $\begin{array}{l}\text { Year or } \\
\text { Period }\end{array}$ & $\begin{array}{c}\text { All } \\
\text { Properties }\end{array}$ & Office & Retail & Industrial & $\begin{array}{c}\text { Annual } \\
\text { Property-Type } \\
\chi^{2}\end{array}$ & $\begin{array}{c}\text { Annual Comp } \\
\text { of Sample P } \\
\chi^{2} \\
\end{array}$ \\
\hline 2003 & 1.423 & 1.441 & 1.510 & 1.324 & 15.17 & 0.55 \\
\hline 2002 & 1.417 & 1.504 & 1.526 & 1.215 & 54.83 & 1.23 \\
\hline 2001 & 1.433 & 1.390 & 1.513 & 1.311 & 20.82 & 0.06 \\
\hline 2000 & 1.446 & 1.370 & 1.535 & 1.369 & 18.79 & 0.19 \\
\hline 1999 & 1.440 & 1.422 & 1.434 & 1.488 & $1.58 *$ & 0.02 \\
\hline 1998 & 1.414 & 1.394 & 1.399 & 1.472 & $2.78 *$ & 1.88 \\
\hline 1997 & 1.409 & 1.309 & 1.453 & 1.508 & 18.40 & 2.66 \\
\hline 1996 & 1.322 & 1.271 & 1.306 & 1.280 & $1.04 *$ & 57.55 \\
\hline 1995 & 1.469 & 1.389 & 1.520 & 1.549 & 12.53 & 2.95 \\
\hline 1994 & 1.459 & 1.406 & 1.509 & 1.458 & $6.65 *$ & 1.47 \\
\hline 1993 & 1.517 & 1.541 & 1.570 & 1.581 & $0.41 *$ & 16.88 \\
\hline 1992 & 1.527 & 1.551 & 1.523 & 1.591 & $1.05 *$ & 15.63 \\
\hline 1991 & 1.500 & 1.644 & 1.503 & 1.527 & $6.88 *$ & 10.61 \\
\hline 1990 & 1.632 & 1.645 & 1.605 & 1.610 & $0.61 *$ & 72.88 \\
\hline 1989 & 1.597 & 1.692 & 1.529 & 1.698 & 10.04 & 39.62 \\
\hline 1988 & 1.743 & 1.750 & 1.786 & 1.772 & $0.28 *$ & 107.18 \\
\hline 1987 & 1.615 & 1.706 & 1.546 & 1.854 & 15.47 & 42.23 \\
\hline 1986 & 1.434 & 1.476 & 1.357 & 1.448 & 8.37 & 0.04 \\
\hline 1985 & 1.461 & 1.357 & 1.408 & 1.679 & 25.38 & 1.39 \\
\hline 1984 & 1.349 & 1.273 & 1.345 & 1.426 & 9.80 & 22.14 \\
\hline 1983 & 1.338 & 1.275 & 1.338 & 1.428 & 9.45 & 30.47 \\
\hline 1982 & 1.324 & 1.318 & 1.305 & 1.344 & $0.63 *$ & 35.80 \\
\hline 1981 & 1.283 & 1.366 & 1.265 & 1.234 & $6.79 *$ & 58.55 \\
\hline 1981-03 & 1.448 & 1.431 & 1.471 & 1.425 & 31.80 & \\
\hline $1981-03 \chi$ & & 16.92 & 10.55 & 4.33 & & 521.99 \\
\hline
\end{tabular}

* Statistically significant confidence of $95 \%$ that the characteristic exponent $\alpha$ is identical for the calendar year across all three property types. 
Figure 11

Skewness Parameter $\beta$ for IPD Property Database

Log Annual Total Return Residual Distributions

All Properties, Properties by Type, and Chi-square Goodness of Fit Results

\begin{tabular}{|c|c|c|c|c|c|c|}
\hline $\begin{array}{l}\text { Year or } \\
\text { Period }\end{array}$ & $\begin{array}{c}\text { All } \\
\text { Properties }\end{array}$ & Office & Retail & Industrial & $\begin{array}{c}\text { Annual } \\
\text { Property-Type } \\
\chi^{2}\end{array}$ & $\begin{array}{r}\text { Annual Comp } \\
\text { of Sample P } \\
\chi^{2} \\
\end{array}$ \\
\hline 2003 & -0.026 & -0.371 & 0.111 & 0.094 & 48.40 & 21.02 \\
\hline 2002 & -0.089 & -0.321 & 0.090 & -0.074 & 27.67 & 46.33 \\
\hline 2001 & 0.004 & 0.098 & -0.437 & 0.024 & $4.41 *$ & 15.39 \\
\hline 2000 & 0.123 & 0.379 & -0.098 & 0.090 & 40.22 & 0.09 \\
\hline 1999 & 0.300 & 0.333 & 0.064 & 0.198 & $4.00 *$ & 35.46 \\
\hline 1998 & 0.148 & 0.175 & 0.180 & 0.119 & $0.63 *$ & 0.32 \\
\hline 1997 & 0.261 & 0.242 & 0.028 & 0.258 & $0.81 *$ & 23.05 \\
\hline 1996 & -0.007 & -0.262 & 0.348 & 0.080 & 38.59 & 25.34 \\
\hline 1995 & -0.282 & -0.319 & -0.720 & -0.335 & $0.42 *$ & 238.38 \\
\hline 1994 & -0.177 & -0.270 & -0.402 & -0.114 & 8.39 & 121.68 \\
\hline 1993 & -0.265 & -0.739 & 0.618 & -0.458 & 53.70 & 167.00 \\
\hline 1992 & -0.596 & -1.000 & -1.000 & -0.951 & 22.38 & 321.94 \\
\hline 1991 & -0.248 & -0.781 & -1.000 & -0.161 & 17.75 & 173.57 \\
\hline 1990 & -0.828 & -0.121 & 0.613 & 0.003 & $1.75 *$ & 9.59 \\
\hline 1989 & 0.602 & 0.829 & 0.227 & 0.914 & $5.05 *$ & 63.03 \\
\hline 1988 & 1.000 & 1.000 & 0.041 & 1.000 & $0.00 *$ & 42.92 \\
\hline 1987 & 1.000 & 1.000 & 0.185 & 1.000 & $0.00 *$ & 90.66 \\
\hline 1986 & 0.344 & 0.172 & 0.225 & -0.080 & 78.67 & 60.22 \\
\hline 1985 & 0.344 & 0.167 & 0.012 & -0.227 & 62.53 & 56.39 \\
\hline 1984 & 0.399 & 0.105 & 1.000 & -0.060 & 117.73 & 107.64 \\
\hline 1983 & 0.305 & 0.114 & 0.077 & -0.041 & 63.46 & 42.23 \\
\hline 1982 & 0.428 & 0.337 & 0.112 & -0.132 & 96.59 & 137.16 \\
\hline 1981 & 0.537 & 0.495 & 0.768 & 0.220 & 37.83 & 259.16 \\
\hline 1981-03 & 0.136 & 0.053 & 0.257 & -0.025 & 265.23 & \\
\hline $1981-03 \chi$ & & 48.36 & 145.28 & 71.59 & & 2058.97 \\
\hline
\end{tabular}

* Statistically significant confidence of $95 \%$ that the skewness parameter $\beta$ is identical for the calendar year across all three property types. 
Figure 12

Risk Reduction for Various $\alpha$ and Number of Assets

\begin{tabular}{lrrrrrrr} 
& \multicolumn{7}{c}{ Number of Assets } \\
\cline { 2 - 8 }$\alpha$ & 1 & 2 & 4 & 8 & 10 & 20 & 100 \\
\hline 2.00 & 1 & 0.707 & 0.500 & 0.354 & 0.316 & 0.224 & 0.100 \\
1.90 & 1 & 0.720 & 0.519 & 0.373 & 0.336 & 0.242 & 0.113 \\
1.80 & 1 & 0.735 & 0.540 & 0.397 & 0.359 & 0.264 & 0.129 \\
1.70 & 1 & 0.752 & 0.565 & 0.425 & 0.387 & 0.291 & 0.150 \\
1.60 & 1 & 0.771 & 0.595 & 0.459 & 0.422 & 0.325 & 0.178 \\
1.50 & 1 & 0.794 & 0.630 & 0.500 & 0.464 & 0.368 & 0.215 \\
1.40 & 1 & 0.820 & 0.673 & 0.552 & 0.518 & 0.425 & 0.268 \\
1.30 & 1 & 0.852 & 0.726 & 0.619 & 0.588 & 0.501 & 0.346 \\
1.20 & 1 & 0.891 & 0.794 & 0.707 & 0.681 & 0.607 & 0.464 \\
1.10 & 1 & 0.939 & 0.882 & 0.828 & 0.811 & 0.762 & 0.658 \\
1.00 & 1 & 1.000 & 1.000 & 1.000 & 1.000 & 1.000 & 1.000 \\
0.90 & 1 & 1.080 & 1.167 & 1.260 & 1.292 & 1.395 & 1.668 \\
\hline & & & & & & &
\end{tabular}

Figure 13

Number of Assets Needed for Risk Reduction by the Factor $k$

Factor $k$

\begin{tabular}{rrrrrrrr}
$\alpha$ & 1 & 2 & 4 & 8 & 10 & 20 & 100 \\
\hline 2.00 & 1 & 4 & 16 & 64 & 100 & 400 & 10,000 \\
1.90 & 1 & 5 & 19 & 81 & 130 & 558 & 16,682 \\
1.80 & 1 & 5 & 23 & 108 & 178 & 846 & 31,623 \\
1.70 & 1 & 6 & 29 & 156 & 269 & 1,445 & 71,969 \\
1.60 & 1 & 7 & 41 & 256 & 465 & 2,948 & 215,444 \\
1.50 & 1 & 8 & 64 & 512 & 1,000 & 8,000 & $1,000,000$ \\
1.40 & 1 & 12 & 128 & 1,448 & 3,163 & 35,778 & $10,000,000$ \\
1.30 & 1 & 21 & 407 & 8,192 & 21,545 & 434,307 & $4.6 \times 10^{8}$ \\
1.20 & 1 & 64 & 4,096 & 262,144 & $1,000,000$ & $6.4 \times 10^{7}$ & $1.0 \times 10^{12}$ \\
\hline
\end{tabular}

